International Journal of Instruction e-ISSN: 1308-1470 • www.e-iji.net

Article submission code: 20200930125313

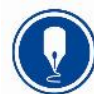

October $2021 \bullet$ Vol.14, No.4

p-ISSN: 1694-609X

pp. 281-300

Received: 30/09/2020

Revision: 10/03/2021
Accepted: 03/04/2021

OnlineFirst: 17/07/2021

\title{
Analysis of Factors Affecting Students' Mathematics Learning Difficulties Using SEM as Information for Teaching Improvement
}

\section{Rahmi Wiganda Elastika}

Master Study Program of Mathematics, Faculty of Mathematics and Natural Sciences, Universitas Padjadjaran, Indonesia, elastikarahmi@ gmail.com

\section{Sukono}

Dr., Department of Mathematics, Faculty of Mathematics and Natural Sciences, Universitas Padjadjaran, Indonesia, sukono@unpad.ac.id

\section{Stanley Pandu Dewanto}

Department of Mathematics, Faculty of Mathematics and Natural Sciences, Universitas Padjadjaran, Indonesia, stanleypd@bdg.centrin.net.id

Students' learning math difficulties are influenced by various factors, both internal factors (themselves) and external factors (from outside the students themselves). One of the external factors that can affect student achievement is the campus facilities and infrastructure where they study. This paper aims to estimate structural equation models, which can represent the relationship between latent variables, and the relationship between latent and indicator variables. Besides, it is also to determine which construct has the most influence on the achievement of four indicators, which include: Campus Environment (KPS), Family Environment (LK), Community Environment (LM), and Seating (TD) towards Self (DS). The research data was obtained through a survey using a questionnaire to Universitas Padjadjaran students in the Mathematics Study Program. Data were measured using a Likert scale and using a simple random sampling technique. Data analysis was performed using Structural Equation Modelling (SEM). The results of the data analysis show that the parameter estimators of the four indicators are $0.29,0.34$, 0.14 , and 0.12 respectively, with the R-squared coefficient of determination of 0.90 . So that SEM is an analysis that can provide information that is used to support the learning process policymaking.

Keywords: learning difficulties, campus environment, family environment, community environment, seating, structural equation modelling (SEM)

\section{INTRODUCTION}

Mathematics is a language using carefully, clearly, and accurately described notations. Mathematics is not a knowledge that can become perfect in itself, but it can help people understand and solve social, economic, and natural problems. It grows and develops

Citation: Elastika, R. W., Sukono., \& Dewanto, S. P. (2021). Analysis of Factors Affecting Students' Mathematics Learning Difficulties Using SEM as Information for Teaching Improvement. International Journal of Instruction, 14(4), 281-300. https://doi.org/10.29333/iji.2021.14417a 
because of the thinking and logic processes that form the basis for the formation of mathematics (Esmail et al., 2014; Magen-Nagar, 2016). Mathematics has a very important role because mathematics is a basic science that is widely used in various fields of life. Through mathematics learning, students are expected to develop critical, logical, systematic, careful, effective, and efficient thinking skills. One of the achievements of mathematics formation can be assessed by the success of students in solving mathematics problems (Diezmann et al., 2016; Nasrin \& Nasreen, 2018). For that, it is necessary to evaluate student learning outcomes to create quality education and quality undergraduate quality. Students with quality can be seen from their learning achievement (DeFreitas \& Rinn, 2013). Achievement of learning mathematics is a success that a person gets after learning mathematics both in the cognitive, affective, and psychomotor aspects according to the competence of the subject matter of mathematics being studied (Al-Agili et al., 2017). Many factors can affect learning achievement, one of which is that students experience difficulties in the learning process itself (Wonglorsaichon et al., 2014; Davadas \& Lay, 2018; Albelbisi \& Yusop, 2019).

Learning difficulties are conditions when students experience certain obstacles to participate in the learning process and achieve optimal learning outcomes (Diezmann et al., 2016). Besides, learning difficulties are things or disorders that fail or at least become a distraction that can hinder learning progress (Nasrin \& Nasreen, 2018). In line with the previous opinion, the learning difficulties experienced by students indicate a gap or distance between the expected academic achievement and the actual academic achievement achieved by students (Shakir \& Sharma, 2018; Nezhad \& Vahedi, 2011). Deep learning difficulties in teaching mathematics to involve an appreciation of the structure of mathematics, the availability of learning resources, the quality of the lecturers, the curriculum, the learning itself, and the value given to the subject by society (Fin \& Ishak, 2012). Students who experience learning difficulties do not perform well academically for a variety of reasons, including factors such as sensory impairments (weakness in vision or hearing); severe behavioural, psychological, or emotional problems (Poole, 2011). Laziness may lead to low interest and involvement in studying on campus. Given that poor motivation can be associated with learning difficulties (Diezmann et al., 2016; Nasrin \& Nasreen, 2018).

According to Albelbisi \& Yusop (2019), student learning difficulties are influenced by many factors, both internal and external factors. Internal factors that influence such as: problem solving, intelligence, learning motivation, mindset of subjects, and personality. External factors that influence such as: lecturer performance, family support, campus environment, learning methods, and so on. These factors need special attention from several related parties, especially the teaching staff. Acharya (2017), examined the difficulties of public school students in learning mathematics in relation to their learning. The research objective was to explore the causes of learning difficulties in mathematics. The qualitative research design and interviews were conducted with respondent students in three schools of Arghakhanchi district. The results of the analysis show that students, teachers, and parents have an important role in increasing student graduation. Lack of continuity of newly learned mathematical concepts with the basics of previously studied mathematics, anxiety about mathematics, negative perceptions of 
mathematics, the economic conditions and educational background of parents, management systems in schools, lack of school infrastructure, and lack of systems regular school assessments, a major factor in student difficulty in learning mathematics.

In terms of student learning difficulties, it has been a concern of several studies, such as research conducted by Diezmann et al. (2016), by analysing the learning difficulties of mathematics education program students on the subject of real number systems. In this study, data collection techniques were carried out using interview techniques and mathematical tests. In the research of Nasrin and Nasreen (2018), to analyse the learning difficulties of Calculus I in Informatics Engineering students. The data analysed were obtained through a survey conducted using a careful sample of 160 students. Data collection was carried out through questionnaires, validated questions, and final exam scores. All data were analysed using descriptive analysis, factor analysis, and multiple linear regressions. Whereas in the research of Sembiring (2015), which analysed student learning difficulties in Basic Mathematics courses. In this study, the method used is qualitative, with data collection techniques using interviews, tests, and observations.

Based on the description of the problem and referring to research that has been done before, this study intends to analyse the difficulty of learning mathematics for Universitas Padjadjaran students, using different methods of analysis. In this study, an analysis of the learning difficulties of mathematics students was carried out using Structural Equation Modelling (SEM). Research in the field of education using SEM is not something that has never been done. As research Yoda et al. (2017), Zain et al. (2013), Durdyev and Ihtiyar (2019) and Al-Sheeb (2019), researched teacher selfefficacy, instructional quality, and student motivational beliefs: an analysis using multilevel structural equation modelling. However, none of these studies have used SEM as a model to analyse learning difficulties. So, based on this also makes the research conducted in this paper very different from previous studies. This study aims to: (1) identify the factors that affect students' difficulties in learning mathematics; (2) estimate the SEM model to analyse the factors that affect mathematics students' learning disabilities; and (3) analysing research results as information for teaching iimprovement for lecturers.

\section{THEORETICAL BASIS}

\section{Learning Difficulties and Influencing Factors}

Learning difficulties can be interpreted as anything that hinders or slows down a student in learning, understanding, and mastering something to achieve learning outcomes. Students who experience learning difficulties will find it difficult to absorb the subject matter delivered by the lecturer, they will be lazy in learning, and cannot master the material, avoid lessons, and neglect assignments so that they can affect their learning outcomes (Diezmann et al., 2016). Symptoms of learning difficulties will appear in cognitive, motoric, and affective aspects, both in the process and in the learning outcomes achieved. Learning difficulties can even cause a difficult situation and may lead to despair that forces a student to stop halfway through. The existence of learning 
difficulties in students can be detected by students' mistakes in doing assignments and test questions (Nasrin \& Nasreen, 2018).

Students are not always able to get good and maximum learning achievements as expected by parents and lecturers. This is because student achievement is influenced by several factors, including self, environment, learning facilities and infrastructure, and learning, as well as the interaction of all these factors in the learning process. Therefore, the factors that influence learning, if considered properly, can support student achievement. On the other hand, if it is not considered, it will become a factor that creates problems and obstacles to the learning process (Mushtaq \& Khan, 2012; Koç, 2016; Sembiring, 2014). Nauzeer and Jaunky (2019) explain the factors that cause difficulties in learning, namely internal factors or factors from within the students themselves and external factors, namely factors that arise from outside.

\section{Structural Equation Modelling}

Structural Equation Modelling (SEM) includes two things that need to be considered, namely the structural and measurement model. The structural model is intended to measure the relationship between latent variables, while the measurement model is intended to estimate the relationship between the latent and indicator variables (Kim \& Song, 2010; DiLalla, 2000).

\section{Structural Model}

The structural model aims to examine the relationship between the factors that underlie it, or what constitutes a structural arrangement between latent variables into the measurement model and other construct variables based on the theory used. Parameters that represent regression equations for exogenous latent variables are marked by using

the symbol $\gamma$ (gamma), while for regression equations for endogenous latent variables are marked using the symbol $\beta$ (beta) (Otoo et al., 2018).

In general, the form of the structural equation model is described as follows.

Suppose the random variable vectors $\eta^{T}=\left(\eta_{1}, \eta_{2}, \ldots, \eta_{m}\right)$ and $\xi^{T}=\left(\xi_{1}, \xi_{2}, \ldots, \xi_{n}\right)$ represent endogenous and exogenous variables, respectively, can form simultaneous equations based on the system of relationships of linear equations as follows

$$
\eta=\mathrm{B} \eta+\Gamma \xi+\zeta
$$

where the matrix $\mathbf{B}$ and $\boldsymbol{\Gamma}$ is the coefficient matrix, and $\zeta^{T}=\left(\zeta_{1}, \zeta_{2}, \ldots, \zeta_{n}\right)$ is the error vector contained in the structural equation. The element of matrix B influences the variable $\boldsymbol{\eta}$, in other $\boldsymbol{\eta}$ variables. The element $\boldsymbol{\Gamma}$ has a direct influence on the variable $\boldsymbol{\xi}$ in 
the variable $\boldsymbol{\eta}$. It is assumed that the vector $\boldsymbol{\xi}$ does not correlate with $\bar{\zeta}$ and $1-\mathbf{B}$ is a non-singular matrix (Al-Sheeb et al., 2019).

The structural model expression can be obtained using the following description

$$
\begin{aligned}
& \eta=\mathrm{B} \eta+\Gamma \xi+\zeta \\
& \eta-B \eta=\Gamma \xi+\zeta \\
& \eta(1-B)=\Gamma \xi+\zeta \\
& \eta=(1-B)^{-1}(\Gamma \xi+\zeta) .
\end{aligned}
$$

where $\mathbf{B}$ is the coefficient matrix of endogenous latent variables measuring $m \times n ; \Gamma$ is the coefficient matrix of exogenous latent variables having a size of $m \times n ; \boldsymbol{\eta}$ is a vector of endogenous latent variables having a size of $m \times 1$; $\xi$ is a vector of exogenous latent variable having size $n \times 1$; and $\xi$ is the residual random vector of the relationship between $\eta$ and $\xi$ which has a size of $m \times 1$ (Kocakaya \& Kocakaya, 2014; Hwang \& Kuo, 2015; Civelek, 2018).

Measurement Model

The measurement model aims to estimate the relationship between the latent variables and the observed variables. The latent variable being modelled is a factor as the basis for the associated observed variables. The loadings factor (weight) that connects the latent variable with the observed variables which are indicated by using the $\lambda$ (lambda) symbol. A latent variable in SEM is a causal relationship (cause-effect) that occurs between unobserved variables or latent variables. The parameters of the SEM measurement model equation are the loadings factor (weights) of the latent variable against the indicators or related to the simultaneous causal relationship between the variables, which can provide information about the loadings factor (weights) and measurement errors that occur (Civelek, 2018; Eroglu \& Mercangöz, 2013; Kristiana, 2018; Savolainen et al., 2012).

Referring to Civelek (2018), the random vectors $\boldsymbol{\eta}$ and $\boldsymbol{\xi}$ are not measured directly but through the accompanying indicators, namely variables $\boldsymbol{Y}^{T}=\left(y_{1}, y_{2}, \ldots, y_{p}\right)$ and $\boldsymbol{X}^{T}=\left(x_{1}, x_{2, \ldots}, x_{q}\right)$ whose measurements are carried out using the measurement model, and can be stated as follows 


$$
\begin{aligned}
& X=\Lambda_{X} \xi+\delta_{x} \\
& \boldsymbol{Y}=\Lambda_{Y} \xi+\varepsilon_{x}
\end{aligned}
$$

where $X$ is the indicator variable vector of the exogenous variable $q \times 1 ; \Lambda_{X}$ is a matrix for the loading factor ( $\lambda$ ) or the coefficient that shows the relationship between $\boldsymbol{X}$ and $\boldsymbol{\xi}$ measuring $q \times n ; \delta$ is the error vector of the measurement model concerning $X$ of size $q \times 1 ; \boldsymbol{Y}$ is the indicator variable vector of the endogenous variable $p \times 1 ; \boldsymbol{A}_{Y}$ is a matrix for the loading factor $(\lambda)$ or the coefficient that shows the weight of the relationship between $\boldsymbol{Y}$ and $\boldsymbol{\eta}$ measuring $p \times m ; \boldsymbol{\varepsilon}$ is the error vector of the measurement model concerning $\boldsymbol{Y}$ of size $p \times 1$.

\section{Model Parameter Estimation}

Parameter estimation is done to obtain the estimator value from the parameters contained in the SEM model. In the structural equation model, parameter estimation is carried out to determine the estimator value of each parameter specified in the SEM model and is used to form a matrix $\mathbf{\Sigma}$ such that the value of the parameter is close to the value in the sample covariance matrix of the observed variable $\boldsymbol{S}$. Covariance matrix sample $\boldsymbol{S}$ is useful for representing the covariance matrix of the population $\mathbf{\Sigma}$ because the population covariance matrix is not known in the observation (Durdyev \& Ihtiyar, 2019).

Referring to Civelek (2018), there are several characteristics of $F((\boldsymbol{s}-\mathbf{\Sigma}(\theta)))$ as follows: (i) $F((s-\mathbf{\Sigma}(\theta)))$ is scalar; (ii) $F((s-\mathbf{\Sigma}(\theta))) \geq 0$;

$F((S-\mathbf{\Sigma}(\theta)))=0$, valid if only if $\mathbf{\Sigma}(\theta)=S$; and (iv) $F((S-\mathbf{\Sigma}(\theta)))$ is continuous in $\boldsymbol{S}$ and $\mathbf{\Sigma}(\theta)$. Referring to Kim and Song (2010), the Unweighted Least Square (ULS) method will have a compatibility function as follows

$$
F_{U L S}=\frac{1}{2} \operatorname{tr}(s-\mathbf{\Sigma}(\theta))^{2} .
$$


where the $F_{\text {ULS }}$ function provides a minimum value of half the number of squares of each element in the remaining matrix $(\boldsymbol{S}-\mathbf{\Sigma}(\theta))$, where $\boldsymbol{S}$ and $\mathbf{\Sigma}$ are symmetrical and positive definite matrices. This means almost the same as the Ordinary Least Squares (OLS) method. The OLS method is intended to obtain the minimum value of the remaining squares. Meanwhile, the ULS method is intended to obtain a minimum value on the number of squares of each component in the remaining matrix $(s-\mathbf{\Sigma}(\theta))^{2}$. This residual matrix contains the difference between each variety of samples and the estimator value of the SEM model. It's just that the ULS method does not require special assumptions from the distribution of the observed variables along with the identified parameters. So that the ULS method is said to be a consistent estimator.

\section{Model Fit Test}

The suitability (fit) test is intended to generally measure the degree of fit or Goodness of Fit (GOF) between the data and the estimator model. Overall, there are three parts to the GOF test, namely the absolute fittest, the incremental fittest, and the parsimony test (Durdyev \& Ihtiyar, 2019), (Civelek, 2018).

Goodness of Fit Index

The Goodness of Fit Index (GFI) is an absolute fittest because in principle GFI compares the assumed model with no suitable model at all $\mathbf{\Sigma}(\theta)$. The value of GFI ranges from 0 to 1 , if $G F I \geq 0.9$, then it is a good fit, whereas if $0.8 \leq G F I \leq 0.9$, it is called a marginal fit.

\section{Root Mean Square Error of Approximation (RMSEA)}

Root Mean Square Error of Approximation (RMSEA) is used to measure the degree of fit based on the closeness of a model estimator to the observed population. RMSEA is an alternative measurement of the suitability of the estimator model needed to reduce the sensitivity $\chi^{2}$ to the sample size under observation. Value of RMSEA $\leq 0.05$ indicates a close fit, while $0.05 \leq$ RMSEA $\leq 0.08$ indicates a good fit.

\section{Parsimony Suitability Test}

Models with relatively few parameters are often known as models that have high parsimony or savings. The parsimony test is an effort to obtain the highest level of suitability for each degree of freedom. In this study, the Parsimonious Normed Fit Index (PNFI) was used, taking into account the number of degrees of freedom to achieve a level of compatibility. PNFI is stated as follows 


$$
P N F I=\frac{d f_{h}}{d f_{i}} \times N F I_{x}
$$

where $d f_{h}$ is the degree of freedom of the hypothesized mode, $d f_{i}$ is the degree of freedom of the initial model, and $N F I$ is the Normed Fit Index, whereas

$$
N F I=\frac{\left(x^{2}-\chi_{\hat{h}}^{2}\right)}{\chi_{i}^{2}}
$$

A higher PNFI value is best. PNFI was used to compare alternative models, and no recommendation level of fit was accepted. However, when comparing the two models, the difference in the PNFI value of 0.06 to 0.09 indicates a quite large difference in the model (Hair, 1998).

\section{Direct Effect, Indirect Effect, and Total Effect}

The direct effect can be measured based on the value of the path coefficient from one variable to another. The indirect effect is the sequence of paths through one or more intermediate variables in SEM. Referring to Civelek (2018), in testing the indirect effect there are three known variables, namely predictor, mediator, and criterion. Figure 1 shows the position of the predictors, mediators, and criterions in the structure.

How to identify the indirect effect can be done based on four stages, namely: (i) testing the direct effect of the predictor on the criterion; (ii) identify whether the predictor influences the mediator; (iii) identify whether the mediator influences criterion; (iv) identify the influence of the predictor on a criterion by still including the influence of the mediator.

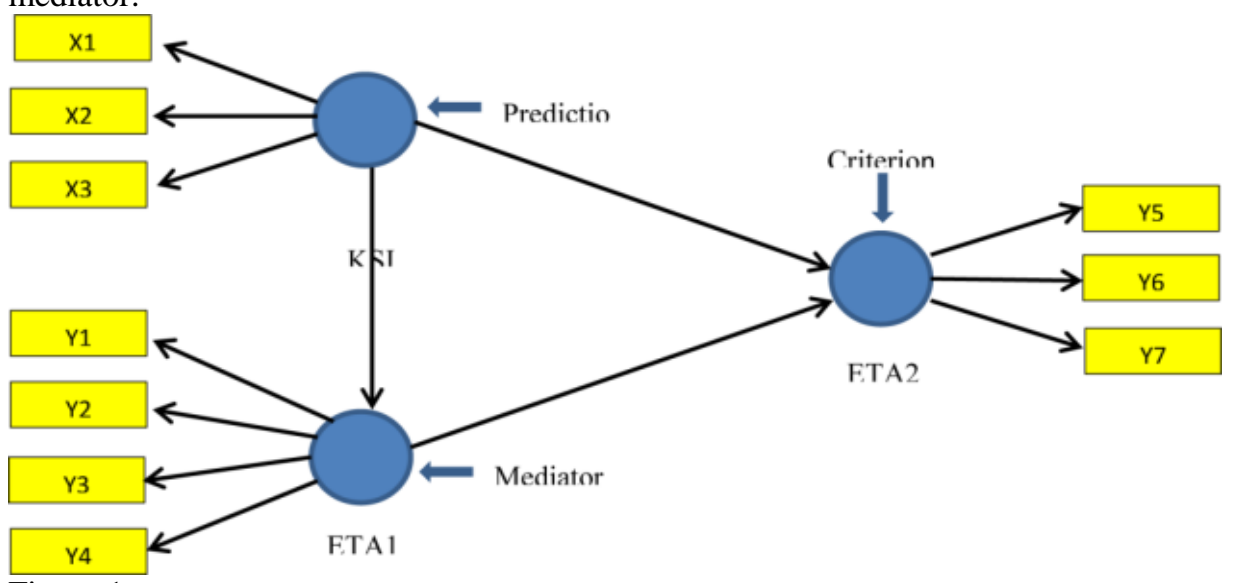

Figure 1

Position of the predictors, mediators, and criterions in SEM 


\section{METHOD}

\section{Research Method}

In this study, a quantitative approach was used with a survey method. The survey method is a method that uses a questionnaire as a means of collecting data. A quantitative approach is a quantitative research method that can be defined as a research method based on the positivism philosophy to examine a particular population or sample, the sampling technique is generally carried out randomly, data collection uses research instruments, data analysis is quantitative / statistical in order to test the hypothesis has been established.

\section{Research subject}

The subject in this study is used to obtain the required information clearly and in depth. The determination of the subject in this study was purposive sampling. This research was conducted at Padjadjaran University with student respondents in the Mathematics study program, especially in mathematics subjects.

\section{Data collection tools}

This study aims to determine the factors that most influence the learning difficulties of mathematics students. To obtain direct data in the form of primary data, the questionnaire form is the most suitable tool in this study.

The questionnaire scale used is a Likert scale. The Likert scale measures commonly used in international studies are the 5-point, 7-point, 9-point, 10-point, and 11-point scales. Thus the Likert scale used in this study is a 5-point measure.

\section{Data Analyzed}

As previously explained, this study analysed the factors that affect the difficulty of learning mathematics for Universitas Padjadjaran students. The data to be analysed were obtained by distributing a questionnaire containing 36 statement items concerning themselves (students) and learning difficulties, to 100 respondents. Furthermore, the collected data were analysed using the SEM approach. The data variables in general consist of five factors, namely Campus Environment, Family Environment, Community Environment, Seating, and Self.

Furthermore, for these five factors, a descriptive statistical test was carried out using the Overall Mean Square analysis method. The test results show that the Campus Environment, Family Environment, Community Environment, Seating, and Self as a whole is good according to the respondent's perception

\section{Data validation}

The measurement model analysis was carried out on exogenous latent variables and endogenous latent variables. Measurements are made to analyse the validity of the measurement model and to analyse the model's reliability. 


\title{
FINDINGS
}

\section{Measurement Model Analysis}

\author{
Validity of the Measurement Model on Exogenous Latent Variables
}

Analysis of the validity of the measurement model on exogenous latent variables, based on the results of the LISREL 8.80 output, it can be seen that the measurement equation for the exogenous coefficient of each variable indicator, namely Campus Environment, Family Environment, Community Environment, and Seating has a $t$-value $\geq 1.96$, which means that the exogenous indicators are all valid and statistically significant at the $5 \%$ level of significance and there is no need for the removal of the indicators. As for the Community Environment and Seating variables, because it only has two indicators, the justification is through the standardized loading factor value. Besides, it can be seen that the standardized loading factor $(\lambda)$ on each indicator of each variable has a value that exceeds the threshold, which is more than 0.50 , so it can be said that the indicators in this study can explain the variable or are valid.

Analysis of the reliability of the model on exogenous latent variables, Hair (1998) states that the reliability requirements are good, that is, if the Construct Reliability value is more than or equal to 0.70 . From the calculation results, it can be seen that the overall value of construct reliability on exogenous latent variables (Campus Environment, Family Environment, Community Environment, and Seating) is 0.87, 0.93, 0.91, and 0.72 which are greater than 0.70 . This shows that the reliability of this measurement model is good and the constructs of exogenous latent variables (Campus Environment, Family Environment, Community Environment, and Seating) have been supported by the data obtained.

Validity of the Measurement Model on Endogenous Latent Variables

Analysis of the validity of the measurement model on endogenous latent variables, based on the results of the LISREL 8.80 output, it can be seen that the measurement equation for the endogenous coefficient of each variable indicator for OCB and Employee Performance has a $t$-value $\geq 1.96$, which means that all endogenous indicators are valid and statistically significant. With a significance level of 5\%, and there is no need for an indicator discharge. Besides, it can be seen that the standardized loading factor $(\lambda)$ on each indicator has a value that exceeds the threshold, which is more than 0.50 , so it can be said that the indicators in this study can explain the variables or are valid.

Analysis of model reliability on endogenous latent variables, according to Hair (1998), a good reliability requirement is if it has a Construct Reliability value of more than or equal to 0.70 . From the calculation results, it can be seen that the overall value of Construct Reliability at endogenous Self is 0.80 which is more than 0.70 . This shows that the reliability of this measurement model is good and the endogenous construct itself has been supported by the data obtained. 


\section{Structural Model Analysis}

After calculating and analysing the Confirmatory Factor Analysis (CFA), the Latent Variable Score (LVS) can be measured for each dimension to reduce it to an indicator for each variable. Analysis of the structural model includes the following.

\section{Overall Model Fit Test}

The fit test aims to measure the Goodness of Fit (GOF) between the data and the estimator model. GOF testing in this study was carried out using the help of LISREL 8.80 software, and the results are given in Table 1 .

Table 1

Goodness of fit (GOF) of structural equation model (SEM)

\begin{tabular}{lll}
\hline GOF Measure & Value & Fit Level \\
\hline Goodness of Fit Index (GFI) & 0.88 & Marginal Fit \\
\hline Root Mean Square Error of Approximation (RMSEA) & 0.07 & Good Fit \\
\hline Non-Normed Fit Index (NNFI) & 0.97 & Good Fit \\
\hline Normed Fit Index (NFI) & 0.95 & Good Fit \\
\hline Relative Fit Index (RFI) & 0.98 & Good Fit \\
\hline Incremental Fit Index (IFI) & 0.98 & Good Fit \\
\hline Comparative Fit Index (CFI) & 0.98 & Good Fit \\
\hline
\end{tabular}

Table 1 show that the GFI value of 0.88 is included in the marginal fit category, which means that the value is still below 0.9 but still in the range of 0.80 to 0.90 . However, the scores of RMSEA, NFI, RFI, NNFI, IFI, and CFI all fall into the good fit category. So, it can be concluded that the overall fit of the model is very good.

\section{Causal Relationship Analysis}

After analysing the results of the Goodness of Fit model under study, the next step is to analyse the causal relationship in the model. Statistical testing for the causal relationship of this structural model was carried out at a significance level of $5 \%$ so that the critical value of the t-value was \pm 1.96 . The estimation results of all the research causal relationships can be seen based on the LISREL 8.80 output which is presented in Figures 2 and 3. 


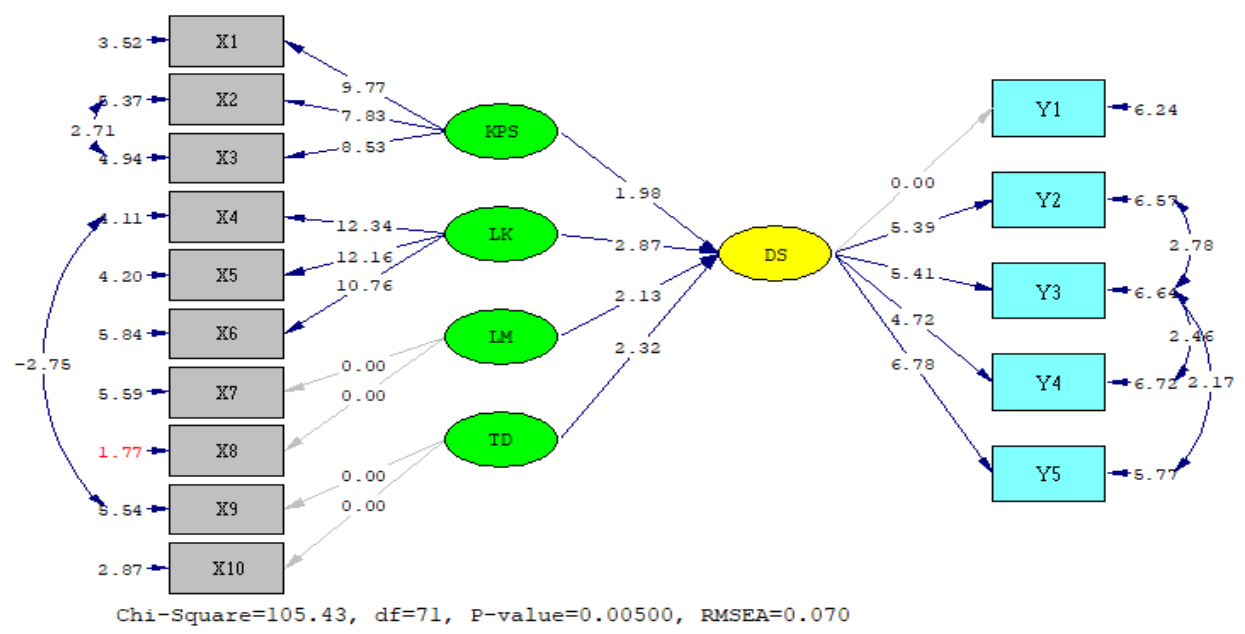

Figure 2

Structural model (t-value)

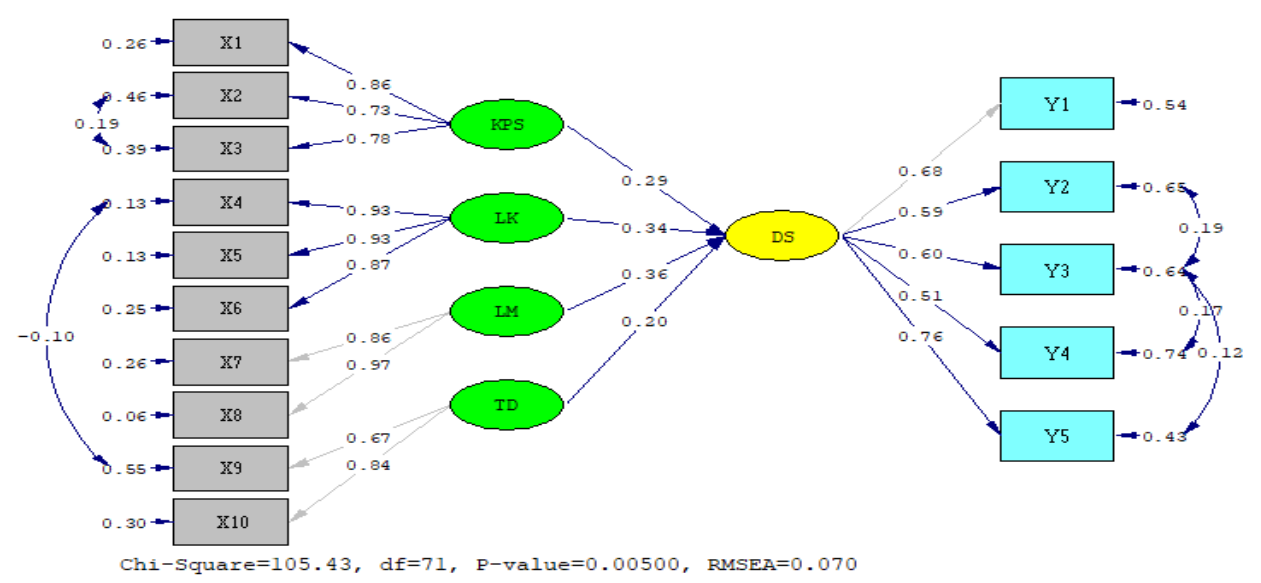

Figure 3

Structural model (Standardized Solution)

From the results of the LISREL 8.80 output for the causal relationship equation above, it can be seen as follows.

t-value and Structural Equation Coefficient. From the causal equation above, a t-value with an absolute value of more than 1.96 means that the path coefficient is significant (Wijayanto, 2008). From Figures 2 and 3, it can be seen that there are four significant path coefficients and no insignificant path coefficients. The interpretation of the path coefficient will be further explained in the hypothesis testing section. 
The coefficient of determination $\left(R^{2}\right)$ and the Structural Equation Model (SEM) are as follows:

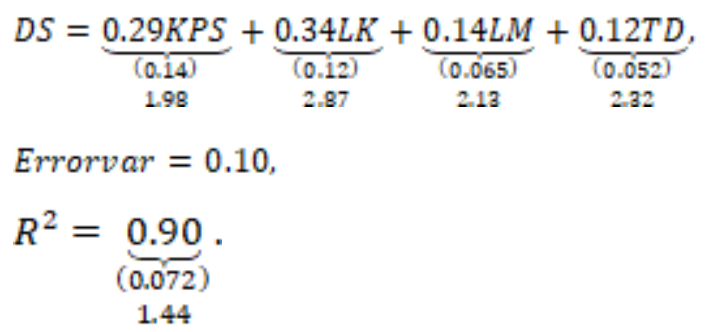

From the structural form equation above, you can see the $R^{2}$ value of each equation. The value of $R^{2}$ serves to show how much each independent variable can explain the dependent variable, here is an analysis of the structural form equation. The Self variable has a $R^{2}$ of 0.90 , this figure shows that the Campus Environment, Family, Society, and Seating can explain $90 \%$ of the variant of Self, while the rest is explained by other factors.

\section{Hypothesis test}

Hypothesis testing is carried out on the direct influence, as well as the relationship between the Environment and Self variables on student learning difficulties, as follows.

Direct Influence. In this study, there are four hypotheses on the direct influence on self. Hypothesis testing analysis was carried out with a significance level of 5\%, resulting in a critical $\mathrm{t}$-value of \pm 1.96 . The hypothesis is accepted if the $\mathrm{t}$-value obtained is more than or equal to 1.96 , while the hypothesis is not supported if the $\mathrm{t}$-value obtained is less than 1.96. The results of tests carried out with the help of LISREL 8.80 output software are given in Table 2.

Table 2

Hypothesis testing for the research model $\mathrm{H} 1-\mathrm{H} 4$

\begin{tabular}{|c|c|c|c|c|}
\hline Hypothesis & Statement & $t$-count & t-table & Information \\
\hline $\mathrm{H} 1$ & Campus environment affects the Self & 1.98 & \multirow{4}{*}{1.96} & Significant \\
\hline $\mathrm{H} 2$ & Family environment affects the Self & 2.87 & & Significant \\
\hline $\mathrm{H} 3$ & Community environment affects the Self & 2.13 & & Significant \\
\hline $\mathrm{H} 4$ & Seating affects the Self & 2.32 & & Significant \\
\hline
\end{tabular}

Table 2 contains the conclusions of the results of the research model hypotheses, which are explained as follows.

1) H1: Campus Environment has a positive influence on Self. Based on the results of data processing from the structural model, the output result is a t-value of 1.98. The result of the t-value shown by $\mathrm{H} 1$ is greater than 1.96 , so it can be concluded that the Campus Environment variable has a significant positive effect on self. Thus, $\mathrm{H} 1$ can be 
accepted, and it can be concluded that the better the campus environment is felt by the respondent, the better the students themselves will be.

2) H2: The Family Environment has a positive influence on self. Based on the results of data processing from the structural model, the output is a t-value of 2.87. The result of the t-value shown by $\mathrm{H} 2$ is greater than 1.96 , so it can be concluded that the Family Environment variable has a significant positive effect on students self. Thus, $\mathrm{H} 2$ is acceptable, and it can be concluded that the better the family environment is felt by the respondent, the better the student's self.

3) H3: Community Environment has a positive influence on self. Based on the results of data processing from the structural model, the output results in the form of a t-value of 2.13. The result of the t-value shown by hypothesis 3 is greater than 1.96, so it can be concluded that the Community Environment variable has a significant positive effect on students' self. Thus, $\mathrm{H} 3$ can be accepted, and it can be concluded that the better the community environment felt by the respondent, the better the student's self.

4) H4: Seating has a positive influence on self. Based on the results of data processing from the structural model, the output results in the form of a t-value of 2.32. The result of the t-value shown by $\mathrm{H} 4$ is greater than 1.96 , so it can be concluded that the Seat variable has a significant positive effect on students' self. Thus, $\mathrm{H} 4$ can be accepted, and it can be concluded that the better the seat perceived by the respondent, the better the student's self.

Relationship between Environmental Variables and Self to Student Learning Difficulties. After analysing the structural model, the next step is to analyse the factors that influence the learning difficulty variable, using the Pearson correlation for each indicator of the research variable to the learning difficulty variable. The results are presented in Table 3, the table is the correlation matrix for each indicator of each research variable on the learning difficulty variable 
Table 3

Correlation of each indicator to the learning difficulty variable

\begin{tabular}{|c|c|c|c|c|c|}
\hline Variables & Indicators & $\begin{array}{l}\text { Relationshi } \\
\text { p Value }\end{array}$ & Category & $\begin{array}{l}\text { Direction of } \\
\text { Relationships }\end{array}$ & Conclusion \\
\hline \multirow{3}{*}{$\begin{array}{l}\text { Campus } \\
\text { Environment }\end{array}$} & Reading material & $-.736^{* *}$ & Strong & $\begin{array}{l}\text { Reverse } \\
\text { Relationship }\end{array}$ & Significant \\
\hline & $\begin{array}{l}\text { Teaching materials are too } \\
\text { high }\end{array}$ & $.725^{* *}$ & Strong & $\begin{array}{l}\text { Unidirectional } \\
\text { Relationship }\end{array}$ & Significant \\
\hline & $\begin{array}{l}\text { The learning arrangement } \\
\text { is too dense }\end{array}$ & $.671^{* *}$ & Strong & $\begin{array}{l}\text { Unidirectional } \\
\text { Relationship }\end{array}$ & Significant \\
\hline \multirow{3}{*}{$\begin{array}{l}\text { Family } \\
\text { Environment }\end{array}$} & Family economy & $-.559 * *$ & $\begin{array}{l}\text { Strong } \\
\text { enough }\end{array}$ & $\begin{array}{l}\text { Reverse } \\
\text { Relationship }\end{array}$ & Significant \\
\hline & Family problem & $-.547 * *$ & $\begin{array}{l}\text { Strong } \\
\text { enough }\end{array}$ & $\begin{array}{l}\text { Reverse } \\
\text { Relationship }\end{array}$ & Significant \\
\hline & Parents attention & $-.467 * *$ & $\begin{array}{l}\text { Strong } \\
\text { enough }\end{array}$ & $\begin{array}{l}\text { Reverse } \\
\text { Relationship }\end{array}$ & Significant \\
\hline \multirow{2}{*}{$\begin{array}{l}\text { Community } \\
\text { Environment }\end{array}$} & $\begin{array}{l}\text { Community environmental } \\
\text { conditions }\end{array}$ & $-.733 * *$ & Strong & $\begin{array}{l}\text { Reverse } \\
\text { Relationship }\end{array}$ & Significant \\
\hline & Friendly association & $-.716^{* *} *$ & Strong & $\begin{array}{l}\text { Reverse } \\
\text { Relationship }\end{array}$ & Significant \\
\hline \multirow{2}{*}{ Seat(ing) } & $\begin{array}{l}\text { Lacking seating } \\
\text { atmosphere }\end{array}$ & 0.108 & $\begin{array}{l}\text { Very } \\
\text { weak }\end{array}$ & $\begin{array}{l}\text { Unidirectional } \\
\text { Relationship }\end{array}$ & $\begin{array}{l}\text { Not } \\
\text { significant } \\
\end{array}$ \\
\hline & Seating distance & $-.301 * *$ & Weak & $\begin{array}{l}\text { Reverse } \\
\text { Relationship }\end{array}$ & Significant \\
\hline \multirow{5}{*}{ Self } & Interest & $-.473 * *$ & $\begin{array}{l}\text { Strong } \\
\text { enough }\end{array}$ & $\begin{array}{l}\text { Unidirectional } \\
\text { Relationship }\end{array}$ & Significant \\
\hline & Poor health & $.506^{* *}$ & $\begin{array}{l}\text { Strong } \\
\text { enough }\end{array}$ & $\begin{array}{l}\text { Unidirectional } \\
\text { Relationship }\end{array}$ & Significant \\
\hline & Ability to follow lessons & $-.542 * *$ & $\begin{array}{l}\text { Strong } \\
\text { enough }\end{array}$ & $\begin{array}{l}\text { Reverse } \\
\text { Relationship } \\
\end{array}$ & Significant \\
\hline & Study habits & $-.417 * *$ & $\begin{array}{l}\text { Strong } \\
\text { enough }\end{array}$ & $\begin{array}{l}\text { Unidirectional } \\
\text { Relationship }\end{array}$ & Significant \\
\hline & Mastery of the material & $-.707 * *$ & Strong & $\begin{array}{l}\text { Unidirectional } \\
\text { Relationship } \\
\end{array}$ & Significant \\
\hline
\end{tabular}

Note: *significant at the $5 \%$ level

Table 3 shows that almost all the indicators in each research variable are factors that affect learning difficulties, except for the indicator "lack of sitting atmosphere". This is because these indicators have a $\mathrm{p}$-value of more than $5 \%$. The indicators that have a strong relationship category to the learning difficulty variable are reading materials, teaching materials that are too high, learning implementation is too dense, community environmental conditions, friendly associations, and mastery of the material.

The results of the analysis of research indicators as a factor affecting learning difficulties are the supply chain of information for teaching staff and learning program managers, as well as for students themselves. For the teaching staff, this information can be used as a basis for always developing teaching strategies, to present learning materials that are easy for students to understand. For learning managers, this information supply chain can be used as a basis for always improving learning facilities and infrastructure, for example increasing the number of reading books and arranging a teaching schedule that is not too crowded on certain days. For students, this information can be used as 
consideration for choosing a positive community and social environment so that they can concentrate on learning, especially for the subjects being taught in each running semester.

\section{DISCUSSION}

Based on the results of the data analysis above, a discussion can be carried out as follows:

Reading materials variable. The availability of varied reading material is very important to foster students' interest in reading. Reading books is a cognitive activity that includes the process of knowledge absorption, understanding, analytical skills, synthesis skills, and evaluation abilities. Being accustomed to reading, a student will have a wide horizon of knowledge, open creativity, high imagination, advanced and developing thinking and become the forerunner of the empowerment of intelligent and talented humans. Lack of availability of various reading materials has an effect on the lack of interest in reading. Likewise, the lack of varied mathematics reading material can affect the reading interest of mathematics students, so that it will cause difficulties in learning mathematics.

Variable of teaching materials that are too high. The principle of the adequacy of the material being taught should be sufficient in helping students understand the basic competencies being taught. The material shouldn't be too low, and it shouldn't be too high. If it is too low, it will not help to achieve competency standards and basic competencies. Conversely, if it is too high it will be difficult to learn it. Especially for mathematics subjects, if it is too high it will cause difficulties for students to learn it.

Variable of learning implementation is too dense. College schedules that are too busy are often used as complaints by students in studying. Therefore, students must be good at managing time in the following way: write down all the things you will do and when the activity will be completed. So that a student can consistently run it well, he can also provide a reminder in every activity that is carried out. Actually it is not easy for students to carry out all their activities. Because more and more, assignments are getting less and more chaotic and life is not just for going to college, a student still has various activities outside of college. Therefore it is necessary to assess how much priority the activities will be undertaken.

Variable of community environmental conditions. Student activities in society can benefit the development of their personal maturity. But if students take part in community activities too much, it may interfere with the learning process of subject matter from campus. So it is necessary to limit student activities outside the campus so that their main task as a student, namely lectures, can run smoothly, without being disturbed. Activities outside the campus should be activities that support the learning process and benefit the student as a student.

Variable of friendly associations. Social friends do have a huge influence and they penetrate the psyche of students more quickly. The quality of associating with peers can be seen from several aspects, including who he associates with, what he does when he 
socializes, and how intense the interaction is. The quality of associating with peers greatly influences the formation of a student's achievement drive. It is expected that quality associations, in the sense of associations in which peer group members are required to do positive things (good and bring benefits) are also able to have a good influence on learning achievement.

Variable of mastery of the material. Professional competence is an ability that must be possessed by a lecturer in relation to mastering subject matter in a broad and deep manner. Professional competence includes sensitivity or expertise in the field, namely mastery of the materials that must be taught along with its methods, a sense of responsibility for their duties and a sense of community with other teachers' peers. If a lecturer lacks mastery of subject matter, it will affect the learning difficulties of his students.

Finally, the results of the analysis of research indicators as a factor affecting the difficulty of learning mathematics are very useful in providing information for teaching staff and learning program managers, as well as for students themselves. For the teaching staff, this information can be used as a basis for always developing teaching strategies, to present learning materials that are easy for students to understand. For learning managers, this information supply chain can be used as a basis for always improving learning facilities and infrastructure, for example increasing the number of reading books and arranging a teaching schedule that is not too crowded on certain days. For students, this information can be used as consideration for choosing a positive community and social environment so that they can concentrate on learning, especially for the subjects being taught in each running semester.

\section{CONCLUSION}

In this paper, research on Structural Equation Model (SEM) has been conducted to analyse the factors that affect the difficulty of learning mathematics for students at Universitas Padjadjaran in the Mathematics Study Program. Based on the results of the identification, it can be concluded that the factors that affect the difficulty of students learning mathematics include: Campus Environment (KPS), Family Environment (LK), Community Environment (LM), and Seating (TD), which significantly affect the students Self (SD). The estimation results show that the Structural Equation Model (SEM) estimator which gives an R-Square determination value of 0.90 or $90 \%$, which can explain the influence of the Campus Environment, Family Environment, Community Environment, and Seating on students Self so that $10 \%$ is influenced by other factors. The results of the research can be used as information for learning program managers, lecturers as teachers, and students as learning citizens, to always improve their performance to reduce the level of difficulty in learning mathematics.

\section{ACKNOWLEDGMENTS}

Acknowledgments are conveyed to the Director of General of Higher Education of the Republic of Indonesia (Deputy for Strengthening and Development of the Ministry of Research and Technology/National Research and Innovation Agency), and Chancellor, Director of the Directorate of Research, Community Engagement, and Innovation, and 
the Dean of the Faculty of Mathematics and Natural Sciences, Universitas Padjadjaran, who have provided the Master with the Contract Number: 1827/UN6.3.1/LT/2020. Thesis Research Grant. This grant is intended to support the implementation of research and publication of master students.

\section{REFERENCES}

Acharya, B.R. (2017). Factors Affecting Difficulties in Learning Mathematics by Mathematics Learners International Journal of Elementary Education. 6(2), 8-15.

Albelbisi, N. A., \& Yusop, F. D. (2019). Factors Influencing Learners' Self -Regulated Learning Skills in a Massive Open Online Course (MOOC) Environment. Turkish Online Journal of Distance Education, 20(3), 1-16.

Al-Agili, M. Z. G., Mamat, Abdullah, M. L., \& Maad, H. A. (2013), Path Analysis of the Factors Influencing Students' Achievement in Mathematics. Australian Journal of Basic and Applied Sciences, 7(4), 437-442, 2013.

Al-Sheeb, B., Hamouda, A., and Abdella, G. (2019). Modeling of Student Academic Achievement in Engineering Education Using Cognitive and Non-Cognitive Factors. Journal of Applied Research in Higher Education, 11(2), 178-198.

Civelek, M. E., Essentials of Structural Equation Modeling (March 12, 2018). Essentials of Structural Equation Modeling (2018), Available at SSRN: https://ssrn.com/ $\underline{\text { abstract }=3338325}$

Davadas, S. D., \& Lay, Y. F. (2018). Factors Affecting Students' Attitude Toward Mathematics: A Structural Equation Modeling Approach." EURASIA Journal of Mathematics, Science and Technology Education, 14(1), 517-529, 2018

DeFreitas, S. C., \& Rinn, A. (2013), Academic Achievement in First Generation College Students: The Role of Academic Self-Concept. Journal of the Scholarship of Teaching and Learning, 13(1), 57-67.

Diezmann, C. M., Stevenson, M. K., \& Mercer, K. L. (2016), Mathematics Learning Difficulties: An Australasian Perspective. 2nd International STEM in Education Conference, pp. 2004-2009.

DiLalla, L. F. (2000). Structural equation modeling: Uses and issues. In Handbook of applied multivariate statistics and mathematical modeling (pp. 439-464). Academic Press.

Durdyev, S., and Ihtiyar, A. (2019). Structural Equation Model of Factors Influencing Students to Major in Architecture, Engineering, and Construction. Journal of Professional Issues in Engineering Education and Practice, 145(2), 05018019.

Eroglu, E., \& Mercangöz, A. (2013). A Path Model for Analyzing Undergraduate Students' Achievement. Journal of WEI Business and Economics, 2(3), 1-8. 
Esmaili, S., Makui, A., \& Hafezalkotob, A. (2014). Introducing a Mathematical Model in Supply Chain by Adding Trust Flow. Journal of Industrial and Systems Engineering, 7(1), 80-103.

Fin, L. S., \& Ishak, Z. (2012). A Priori Model of Students Academic Achievement: The Effect of Gender as Moderator. Procedia - Social and Behavioral Sciences, 65, 10921100 .

Hair, J. F. (1998), Multivariate Data Analysis. New York: Prentice Hall.

Hwang, G. J., \& Kuo, F. R. (2015). A Structural Equation Model to Analyse the Antecedents to Students' Web-Based Problem-Solving Performance. Australasian Journal of Educational Technology, 31(4), 400-420.

Kim, M. and Song, J. (2010). A Confirmatory Structural Equation Model of Achievement Estimated by Dichotomous Attitudes, Interest, and Conceptual Understanding. Eurasia Journal of Mathematics, Science and Technology Education, 6(4), 271-285.

Kocakaya, S., \& Kocakaya, F. (2014). A Structural Equation Modeling on Factors of How Experienced Teachers Affect the Students' Science and Mathematics Achievements. Hindawi Education Research International, 2014, 490371.

Koç, M. (2016). Learning Analytics of Student Participation and Achievement in Online Distance Education: A Structural Equation Modeling. Educational Sciences: Theory \& Practice, 17(6), 1893-1910.

Kristiana, I. F. (2018). Teacher Efficacy in the Implementation of Inclusive Education: A Literature Review. Journal of Educational, Health and Community Psychology, 7(2), 139-152.

Magen-Nagar, N. (2016). The Effects of Learning Strategies on Mathematical Literacy: A Comparison Between Lower and Higher Achieving Countries. International Journal of Research in Education and Science, 2(2), 306-321.

Mushtaq, I., \& Khan, S. N. (2012). Factors Affecting Students' Academic Performance. Global Journal of Management and Business Research, 12(9), 17-22.

Nasrin, A., \& Nasreen, A. (2018), Learning in Mathematics: Difficulties and Perceptions of Students. Journal of Educational Research, 21(1), 147-163.

Nauzeer, S., and Jaunky, V. C. (2019). Motivation and Academic Performance: A SEM Approach. International Journal of Environmental \& Science Education, 14(1), 41-60.

Nezhad, A. S., \& Vahedi, M. (2011). The Role of Educational Psychology in Teacher Education Programs. Procedia Social and Behavioral Sciences, 30, 327-330.

Otoo, D., Iddrisu, W. A., Kessie, J. A., \& Larbi, E. (2018). Structural Model of Students' Interest and Self-Motivation to Learning Mathematics. Hindawi Education Research International, 2018, 9417109. 
Poole, S. M. (2011). The Relationship Between External Accountability Policy and Internal Accountability: A Cross-State Analysis of Charter and Traditional Public Schools." Journal of School Choice, 5(3), 261-280.

Savolainen, H., Engelbrecht, P., Nel, M., \& Malinen, O. P. (2012). Understanding Teachers' Attitudes and Self-Efficacy in Inclusive Education: Implications for Preservice and in-service teacher education. European Journal of Special Needs Education, 27(1), 51-68.

Sembiring, M. G. (2014). Student satisfaction and persistence: Imperative features for retention in Open and Distance Learning. In 28th Annual Conference of the Asian Association of Open Universities (AAOU 2014) (pp. 250-258).

Sembiring, M. G. (2015). Validating student satisfaction related to persistence, academic performance, retention and career advancement within ODL perspectives. Open Praxis, 7(4), 325-337.

Shakir, M., \& Sharma, S. (2018). Using Educational Psychology for Better TeachingLearning Environment. International Journal of Education, 8, 20-28.

Wijayanto, S. H. (2008). Structural Equation Modeling with LISREL 8.8. Yogyakarta: Graha Ilmu.

Wonglorsaichon, B., Wongwanich, S., \& Wiratchai, N. (2014). The Influence of Students School Engagement on Learning Achievement: A Structural Equation Modeling Analysis. Procedia - Social and Behavioral Sciences, 116, 1748-1755.

Yada, A., Tolvanen, A., and Savolainen, H. (2017). Teachers' Attitudes and Selfefficacy on Inclusive Education: A Comparative Analysis between Japan and Finland. ECER: European Educational Research Association, 1-5.

Zain, O. M., Jan, M. T., \& Ibrahim, A. B. (2013). Factors Influencing Students' Decisions in Choosing Private Institutions of Higher Education in Malaysia: A Structural Equation Modelling Approach. Asian Academy of Management Journal, 18(1), 75-90. 